\title{
sciendo
}

\section{GRADUALLY INCREASING VITAMIN E DOSE ALLOWS INCREASING DIETARY POLYUNSATURATION LEVEL WHILE MAINTAINING THE OXIDATION STATUS OF LIPIDS AND PROTEINS IN CHICKEN BREAST MUSCLE*}

Piotr Sałek ${ }^{1}$, Paweł Konieczka ${ }^{2,3 \bullet}$, Wiesław Przybylski ${ }^{1}$, Danuta Jaworska ${ }^{1}$, Aleksandra Rosikiewicz ${ }^{1}$, Katarzyna Olszewska ${ }^{2,4}$, Magdalena Montowska ${ }^{5}$, Dominika Szkopek ${ }^{2}$, Misza Kinsner ${ }^{2}$, Adam Cieślak $^{6}$

\author{
${ }^{1}$ Department of Food Gastronomy and Food Hygiene, Institute of Human Nutrition Sciences, \\ Warsaw University of Life Sciences, Nowoursynowska 159c, 02-776 Warsaw, Poland \\ ${ }^{2}$ Department of Animal Nutrition, The Kielanowski Institute of Animal Physiology and Nutrition \\ Polish Academy of Sciences, Instytucka 3, 05-110 Jabłonna, Poland \\ ${ }^{3}$ Department of Poultry Science, University of Warmia and Mazury, Oczapowskiego 5, \\ 10-719 Olsztyn, Poland \\ ${ }^{4}$ Department of Dietetics, Institute of Human Nutrition Sciences, Warsaw University of Life Sciences, \\ Nowoursynowska 159c, 02-776 Warsaw, Poland \\ ${ }_{5}^{5}$ Department of Meat Technology, Faculty of Food Science and Nutrition, \\ Poznan University of Life Sciences, Wojska Polskiego 31, 60-624 Poznań, Poland \\ ${ }^{6}$ Department of Animal Nutrition, Poznan University of Life Sciences, Wołynska 33, \\ 60-637 Poznań, Poland \\ •Corresponding author: p.konieczka@ifzz.pl
}

\begin{abstract}
Feeding broilers diets high in n-3 long-chain polyunsaturated fatty acids (n-3 PUFA) increases their incorporation into the meat but it may compromise meat quality due to oxidation of lipids and protein. Increased dietary vitamin $\mathbf{E}(\mathrm{vE})$ level downregulates this process, but its excessive level might exceed the physiological requirements for the maintenance of redox balance. This study investigated the sensory characteristics and oxidative status of meat from chickens fed diets supplemented with fish oil (FO) with or without gradually increasing doses of vE. The meat samples were obtained from a total of 27 female broilers of Ross 308 strain ( 9 birds per each of 3 dietary treatments), which were housed according to the standard management practice for commercial chicken houses over a period of 36 days. Chickens were fed diets containing $80 \mathrm{~g} / \mathrm{kg} \mathrm{of}$ supplemental fat, but the diets differed in fat composition; control diet $(80 \mathrm{~g} / \mathrm{kg}$ diet beef tallow as supplemental fat and a basal vE dose); 40 IU of dl- $\alpha$-tocopheryl acetate; diet containing mixture of FO and beef tallow as supplemental fat $(50: 30 \mathrm{w} / \mathrm{w} \mathrm{g} / \mathrm{kg}$ diet) and a basal vE dose (E1), or diet (E2) as diet E1 but with gradually increasing $\mathrm{vE}$ dose (120/240 IU/kg diet fed between days 8-21 and days 22-36, respectively). The highest sensory quality and the lowest oxidative status of meat was found in the control chickens. FO decreased the sensory quality of the meat and increased
\end{abstract}

*This work was supported by the Kielanowski Institute of Animal Physiology and Nutrition Polish Academy of Sciences (statutory funds). 
lipid oxidation as well it had an impact on the lipid profile in muscle tissue (PUFA, n-3 ALA, EPA, DHA). Administration of a graded vE dose increased the sensory quality of the meat and did not limit lipid oxidation but maintained protein oxidation balance.

Key words: vitamin E, n-3 fatty acid, lipid oxidation, protein oxidation, broiler chicken

During rearing, broiler chickens can be subjected to stress condition. The factors that contribute to this stress include the animals' living conditions (so-called welfare) and external factors related to nutrition. In addition, in recent decades, broiler chickens have been selected for fast growth and high yield to meet the growing demand for meat products. However, the induced rapid growth can result in some disorders in the birds' physiology, including abnormalities in their meat (Petracci et al., 2019). The main strategy for mitigating the negative consequences of disorders associated with rapid growth involves nutrition as an effective and easy-to-apply solution.

Fatty acids (FA) are a feed component that affects the quality of poultry meat. Despite general dietary recommendations regarding the intake of n-3 long-chain polyunsaturated fatty acids (LC-PUFA), human consumption of LC-PUFA has not increased significantly over the past decade (Givens, 2015). The so-called "western" diet is low in n-3 PUFA (Givens and Gibbs, 2008). LC-PUFA, including eicosapentaenoic acid (EPA, C20:5n-3) and docosahexaenoic acid (DHA, C22:6n-3), play a key role in the growth and development of the body, in the prevention of many diseases and in normal brain development (McCann and Ames, 2005). Although fish and seafood are a rich source of n-3 PUFA in the human diet, their availability in many parts of the world is limited due to their relatively high cost and decreasing resources. Additionally literature data have suggested that dietary alpha-linolenic acid (ALA) increases the levels of omega-3 long-chain polyunsaturated fatty acids ( $n-3$ LC-PUFAs; Wang et al., 2017). Hence, increased consumption of broiler chicken meat, which can be used as a "carrier" of n-3 FA, may be an alternative. This solution is particularly justified because enrichment of the LC-PUFA content of meat can easily be obtained by modifying the FA composition of the broiler diet, and with using byproducts as a source of LC-PUFA (Konieczka et al., 2015, 2017 a, b; Ribeiro et al., 2013). One way to enrich feed with LC-PUFA is fish oil supplementation. Rymer and Givens (2006) showed that after the addition of $40 \mathrm{~g} / \mathrm{kg}$ fish oil to the broiler diet, the meat originating from the breast muscle (without skin) contained approximately $1500 \mathrm{mg} / \mathrm{kg}$ LC-PUFA n-3 and meat from femoral muscles (without skin) contained approximately $1000 \mathrm{mg} / \mathrm{kg}$ LC-PUFA n-3. In the studies of Kalakuntla et al. (2017), it was shown that supplementation of broiler chicken feed with mustard, linseed and fish oil has a significant impact on the level of PUFA of the n-3 family in chicken meat. In addition, it reduces the n-6 PUFA content and the ratio of n-6:n-3 FA in broiler pectoral and femoral muscles.

Studies have shown that increasing the content of unsaturated FA in the diet of broiler chickens should be combined with the use of antioxidants to prevent lipid oxidation in tissues (Li et al., 2009; Voljč et al., 2013). One of the most effective antioxidants is vitamin E (vE), which inhibits FA oxidation (Rymer and Givens, 2010; Voljč et al., 2013). Li et al. (2009) showed that supplementation of chicken feed with 
$\mathrm{vE}$ increases the stability of FA in the meat and can have a beneficial effect on meat quality and fatty acid composition. However, our previous study provided evidence that increased doses of $\mathrm{vE}$ may exceed the physiological requirements for maintaining the redox balance in the intestinal mucosa and might even induce oxidation of proteins as well as of tissue lipids (Konieczka et al., 2018), or it could destroy intestinal cells through the increase of free radicals and may have an adverse effect (Jafari et al., 2012).

Due to the prooxidative activity of excessive dietary vE when supplemented in one high dose, in the present study we investigated the potential of a gradually increasing vE dose on technological and sensory quality of the meat as well as lipid and protein oxidative balance in case of fish oil addition to chicken diet. It was hypothesized that addition of FO to chicken diet, although decreasing sensory quality of meat and fat stability but gradually increasing dose of $\mathrm{vE}$, shall efficiently counteract fat and protein oxidation.

\section{Material and methods}

\section{Material}

\section{Birds, housing, diets, and experimental design}

All procedures conducted during the present study were approved by the 3rd Local Animal Care and Ethics Committee in Warsaw, Poland (resolution No. WAW2/54/2017), and were performed in accordance with the principles of the European Union (recommendation 2007/526/CE) and Polish Law on Animal Protection.

Chicken meat was obtained as follows; 27 broiler chickens (1-day-old female strain of Ross 308) purchased from a local commercial hatchery were raised together in electrically heated battery brooders and were fed a standard starter diet formulated to meet or exceed their nutritional requirements for 1 week. Birds had free access to feed and water. At 8 day of age, the birds were weighed, and an equal number of chickens for each treatment group ( $\mathrm{n}=9$ each) with body weights close to the group average were randomly allocated to three treatment groups. The conditions of the room were maintained according to standard management practice for commercial chicken houses, and $18 \mathrm{~h}$ light and $6 \mathrm{~h}$ dark cycle was applied. Three isoprotein and isoenergetic diets based on wheat, maize, and soybean meal were prepared and were offered to birds ad libitum (Table 1). The diets were formulated to meet or exceed the nutritional specifications for broilers at respective ages (Aviagen, 2014). Each diet contained $80 \mathrm{~g} / \mathrm{kg}$ of supplemental fat, but the diets differed in fat composition. The main source of added fat in the control group (C) was beef tallow, while in the experimental diets (E1 and E2) there was a mixture of fish oil (FO; oil by-product from codfish liver) and beef tallow (50:30 g/ $\mathrm{kg})$. The FA profiles of the fat sources and diets are shown in Table 2. The diets were supplemented with either a basal amount of $\mathrm{vE}(40 \mathrm{mg} / \mathrm{kg}$ diet; C and E1) or gradually increasing amounts of $\mathrm{vE}(120 \mathrm{mg} / \mathrm{kg}$ and $240 \mathrm{mg} / \mathrm{kg}$ diet on days 8-21 and 22-36, respectively; E2). So, the treatment E1 differed from the treatment E2 with vE dose (basal vs. gradually increasing) to investigate $v E$ effect in PUFA-enriched diet. The control treatment, which was sup- 
plemented with the saturated fat and basal $\mathrm{vE}$ dose (as in the commercial conditions) served as additional comparison to commercial diet regarding different type of fat inclusion and $\mathrm{vE}$ dose. Feed intake was measured, and body weight gain (BWG) and feed conversion ratio (FCR) were calculated from day 8 to day 35 of age.

Table 1. Composition and calculated nutrient content of starter and grower diets, $\mathrm{g} \mathrm{kg}^{-1}$ air-dry matter

\begin{tabular}{l|c|c|c|c}
\hline \multirow{2}{*}{ Components } & \multirow{2}{*}{ Starter } & \multicolumn{3}{c}{ Grower } \\
\cline { 3 - 5 } & & $\mathrm{C}$ & $\mathrm{E} 1$ & $\mathrm{E} 2$ \\
\hline Soybean meal & 411.0 & 417.9 & 417.9 & 417.9 \\
Maize & 392.5 & 317.3 & 317.3 & 317.3 \\
Wheat & 100.0 & 150.0 & 150.0 & 150.0 \\
Beef tallow & 48.5 & 80.0 & 30.0 & 30.0 \\
Fish oil & - & - & 50.0 & 50.0 \\
Limestone & 13.9 & 4.5 & 4.5 & 4.5 \\
Mono-Ca-phosphate & 15.4 & 12.9 & 12.9 & 12.9 \\
NaHCO & 3.0 & 3.0 & 3.0 & 3.0 \\
NaCl & 1.0 & 1.5 & 1.5 & 1.5 \\
L-Lys (78\%) & 1.7 & 0.4 & 0.4 & 0.4 \\
DL-Met (98\%) & 3.0 & 2.5 & 2.5 & 2.5 \\
L-Thr (98\%) & 0.03 & 0.03 & 0.03 & 0.03 \\
Vitamin-mineral premix ${ }^{2}$ & 10.0 & 10.0 & 10.0 & 10.0 \\
Vitamin E, mg/kg & 40 & 40 & 40 & $120 / 240$ \\
Calculated nutrient content & & & & \\
$\quad$ crude protein & 214.3 & 205.6 & 205.6 & 205.6 \\
$\quad$ crude fat & 72.5 & 103.9 & 103.9 & 103.9 \\
\hline
\end{tabular}

${ }^{1}$ According to Smulikowska and Rutkowski (2005).

${ }^{2}$ Provides (per kilogram of diet): (IU) vit. A, 12,500; vit. $\mathrm{D}_{3}, 3000$; (mg) vit. E, 40; vit. $\mathrm{B}_{1}$, 2; vit. $\mathrm{B}_{2}$, 6.5; biotin, 0.2 ; vit. $\mathrm{B}_{6}, 3.5$; vit. $\mathrm{B}_{12}, 0.022$; vit. $\mathrm{K}_{3}, 3$; nicotinic acid, 45 ; folic acid, 1.2 ; pantothenic acid, 13.6; choline, $500 ; \mathrm{Mn}, 90 ; \mathrm{Zn}, 80 ; \mathrm{Se}, 0.35 ; \mathrm{Cu}, 20 ; \mathrm{Fe}, 50 ; \mathrm{I}, 1$.

${ }^{3}$ All diets contained the basal level of vitamin E (all-rac-alpha-tocopheryl acetate; $40 \mathrm{mg} / \mathrm{kg}$ diet) provided as part of the vitamin-mineral premix; the vitamin E concentration of diet E2 was graded and provided $120 \mathrm{mg} /$ $\mathrm{kg}$ and $240 \mathrm{mg} / \mathrm{kg}$ diet on days 8-21 and days 22-36, respectively.

\section{Sampling procedures}

At 36 days of age, the birds were weighed and were euthanized thereafter for breast meat dissection as described earlier (Estevez and Petracci, 2019). Immediately after slaughter, the birds in each group were plucked and eviscerated, and the right breast muscle (pectoralis major) (excluding skin) was excised, vacuum packaged, and stored frozen at $-18^{\circ} \mathrm{C}$ for 3 months for further analysis.

\section{Methods}

\section{The level of muscle (meat) acidification - pH value}

The muscle (meat) $\mathrm{pH}$ value was measured 15 min after sampling at three points of the pectoral "head" using a 330i WTW ${ }^{\circledR} \mathrm{pH}$ meter (Weilheim, Germany; meas- 
ured in triplicate). The device was equipped with a dedicated SenTix ${ }^{\circledR}$ SP Number 103645 penetrating electrode designed for $\mathrm{pH}$ measurement directly in meat and meat products.

\section{Instrumental measurement of color parameters}

The color parameters were measured 24 hours after slaughter. The CIE LAB $\left(\mathrm{L} * \mathrm{a}^{*} \mathrm{~b}\right.$ ) system (color space) was used. A CR-310 Chroma Meter with a D65 illuminant (light source) from Konica Minolta ${ }^{\circledR}$ (Osaka, Japan) was used for measurements. The analysis was performed in three locations on the dorsal surface of each pectoral muscle in three replicates, and the individual measurements were averaged. The meat samples free from color defects, bruising and hemorrhages were cut and bloomed for $1 \mathrm{~h}$ at $4^{\circ} \mathrm{C}$ with no surface covering prior to color measurements.

\section{Determination of the basic composition of muscle tissue}

The analyses of the basic composition of meat derived from the muscle included analysis of crude protein, dry matter, crude ash and ether extract content. The tests were conducted at the Analytical Center of the Warsaw University of Life Sciences. All analyses were performed in triplicate. Protein content was measured according to ISO standard 1871:2009 (ISO 1871, 2009) (the Kjeldahl method; FOSS Tecator ${ }^{\mathrm{TM}}$ 1035 Analyzer). Each individual sample weighed $0.2-0.4 \mathrm{~g}$. The samples were mineralized in sulfuric acid with the addition of Kjeldahl tabs as catalyst. The nitrogen content of the samples was determined by titration with $\mathrm{HCl}$. Fat content was obtained by the Soxhlet method (ISO 1444, 2000) with ether extraction. Each individual sample, as raw meat, weighed approximately $5 \mathrm{~g}$. Water content was evaluated according to the Association of Official Analytical Chemists (AOAC) standard by drying the meat samples in an oven at $105^{\circ} \mathrm{C}$ for $3 \mathrm{~h}$. Ash content was determined according to the AOAC standard. Individual samples weighing 3-4 g were incinerated in a Heraeus furnace for $12 \mathrm{~h}$ at $550^{\circ} \mathrm{C}$.

\section{Cooking yield and defrosting losses}

The cooking yield was determined using meat samples (average weight $265 \mathrm{~g}$ ) subjected to heat treatment (cooking). Cooking was performed simultaneously in two dishes of equal size with matching lids (one sample per dish). Each dish contained 2 liters of water containing $0.8 \%$ table salt. The heat treatment was continued until the geometrical center of the sample (the so-called fillet "head") reached a temperature of $80^{\circ} \mathrm{C}$ as measured by an electronic thermometer (TP-151-125-2-SPEC ${ }^{\circledR}$, Poland). After cooking, the samples were cooled to room temperature $\left(\sim 24^{\circ} \mathrm{C}\right)$. The samples were then weighed, and the yield was calculated based on the difference in mass before and after cooking. Defrosting losses were determined on the basis of the weight difference before and after defrosting.

\section{Sensory quality}

The sensory quality of the meat was determined using meat samples (average weight $265 \mathrm{~g}$ ) collected from the pectoral muscle and subjected to heat treatment. Cooking was performed simultaneously in two dishes of equal size with matching 
lids (one sample from each group per dish) in water containing $0.8 \%$ salt. The heat treatment was continued until the geometrical center of the sample (the so-called fillet "head") reached a temperature of $80^{\circ} \mathrm{C}$ as measured by an electronic thermometer TP-151-125-2-SPEC ${ }^{\circledR}$, Poland). After heat treatment, the samples were cooled to room temperature $\left(\sim 24^{\circ} \mathrm{C}\right)$ and prepared for sensory evaluation. The meat samples were divided into equal-sized portions ( $20 \mathrm{~g})$ and placed in disposable, odorless plastic boxes with matching lids.

To assess the sensory quality of the meat, the Quantitative Descriptive Analysis (QDA) method (ISO 13299.2, 2003) was used. As a tool, an unstructured linear scale $(100 \mathrm{~mm})$ was converted into numerical values (0-10 convenient units (c.u.)). Fifteen quality attributes (4 odor, 2 color, tenderness, juiciness, 6 flavor attributes and overall quality) were selected and evaluated. Most of the tested attributes were scored as no intensity - high intensity, and overall quality was scored as very low to very high (Table 2). The evaluation panel consisted of 10 persons who were familiar with the scaling methods and had been trained in accordance with ISO 8586 (2012). The two independent sessions (replications) were conducted so each sensory mean value was based on 20 individual results. The assessors were experienced in the assessment of meat and meat products. The meat samples were evaluated at room temperature $\left(24 \pm 2^{\circ} \mathrm{C}\right)$ within 3 hours of heat treatment. The assessment was conducted in rooms illuminated by daylight. Between sessions, the panelists consumed hot tea without sugar to neutralize the taste.

\section{Susceptibility of fat to oxidative processes during storage}

The level of fatty acid oxidation in raw meat $(\mathrm{mg} / \mathrm{kg}$ ) was assessed by the TBARS - malondialdehyde content (MDA - malondialdehyde) method (Shahidi, 1990). Briefly, $2 \mathrm{~g}$ of ground meat sample and $5 \mathrm{~cm}^{3}$ of $10 \%$ trichloroacetic acid were placed in a centrifuge tube. The mixture was intensively mixed and ground. Then, $5 \mathrm{~cm}^{3}$ of $0.02 \mathrm{M}$ 2-thiobarbituric acid (TBA) acid solution was added to the tube, the contents of the tube were mixed, and the tubes were centrifuged at 4,000 rpm for 10 minutes. After centrifugation, the samples were filtered into glass tubes. The tubes were covered with plastic film and placed in a boiling water bath for $35 \mathrm{~min}$ to allow color development. During this time, a blank sample was prepared $\left(5 \mathrm{~cm}^{3}\right.$ TCA + $5 \mathrm{~cm}^{3}$ TBA). The contents of the tubes were then cooled in cold water. After cooling, the absorbance of the solutions at $532 \mathrm{~nm}$ was measured in a spectrophotometer (Genesys $20^{\circledR}$, Thermo Scientific, USA). The results were expressed as malondialdehyde (MDA) content in meat [mg/kg]. Each sample was analyzed in duplicate, and the average value was taken as the result. The formula shown below allows the solution absorbance to be converted into the MDA content $[\mathrm{mg} / \mathrm{kg}]$ in the tested sample.

\section{Degree of muscle protein oxidation}

The degree of muscle protein oxidation was determined electrophoretically by assessing the degree of polymerization of muscle proteins. Briefly, a crushed sample weighing $0.1 \mathrm{~g}$ was homogenized in $1 \mathrm{ml}$ of sodium phosphate buffer $(10 \mathrm{mM}, 2 \%$ SDS, 25 mM NEM, pH 7.0) in an Ultra-Turrax T25 ${ }^{\circledR}$ (IKA Labortechnik, Staufen, Germany) for $2 \times 20 \mathrm{~s}$ at $9500 \mathrm{rpm}$ and then for $15 \mathrm{~s}$ at $13,500 \mathrm{rpm}$. The sample was 
centrifuged at $14,000 \mathrm{rpm}$ for $10 \mathrm{~min}$ at $10^{\circ} \mathrm{C}$. The collected supernatant was stored at $-80^{\circ} \mathrm{C}$ for further analysis. Determination of protein content was performed using a 2-D Quant Kit ${ }^{\circledR}$ (GE Healthcare Bio-Sciences).

\section{SDS-PAGE electrophoresis for protein polymerization analysis}

Electrophoresis was conducted according to the Laemmli standard protocol. Samples containing $15 \mu \mathrm{g}$ protein were diluted 1:2 in $2 \mathrm{x}$ concentrated assay buffer (4\% w/v SDS, $125 \mathrm{mM}$ Tris-HCl, 20\% v/v glycerol, $0.004 \% \mathrm{w} / \mathrm{v}$ bromophenol blue, $\mathrm{pH}$ 6.8). The samples were then heated at $95^{\circ} \mathrm{C}$ for $5 \mathrm{~min}$ and separated on a $6 \%$ separating gel (acrylamide:bisacrylamide $=100: 1 \mathrm{w} / \mathrm{w}$ ) in a Hoefer SE 250 system (GE Healthcare) at a constant current of $20 \mathrm{~mA} / \mathrm{gel}$ for $1.5 \mathrm{~h}$ or $2.5 \mathrm{~h}$. The gels were stained with Coomassie Brilliant Blue and scanned on an ImageMaster Scanner $^{\circledR}$ (GE Healthcare Bio-Sciences). SDS-PAGE Molecular Weight Broad Range Standards ${ }^{\circledR}$ (Bio-Rad Laboratories, CA) were used as molecular weight standards.

\section{Diagonal electrophoresis to analyze protein oxidation and polymerization}

Diagonal electrophoresis was performed according to the procedure described by Moczkowska et al. (2017). For the first dimension, sample extracts corresponding to $30 \mu \mathrm{g}$ of protein were separated on a $6 \%$ PAGE gel under non-reducing conditions. The samples were prepared according to the procedure described in the previous section. After electrophoresis in the first dimension, individual lanes were excised and incubated in $2 \mathrm{x}$ concentrated assay buffer containing $20 \mathrm{mM}$ DTT for $1 \mathrm{~h}$ at room temperature. The lanes were then applied horizontally to the top of an SDS-PAGE gel $(6 \%$, acrylamide:bisacrylamide $=100: 1 \mathrm{w} / \mathrm{w})$ and separated at a constant current of $20 \mathrm{~mA} / \mathrm{gel}$ for $1.5 \mathrm{~h}$. The gels were stained with Coomassie Brilliant Blue and scanned on an ImageMaster Scanner ${ }^{\circledR}$ (GE Healthcare Bio-Sciences).

\section{Statistical analysis}

The obtained data were analyzed using STATISTICA software version 13.3 (TIBCO Software Inc. 2017, Statistica data analysis software system, version 13; http://statistica.io). Basic descriptive statistics (mean and standard deviation) were calculated. The normality of the distribution of all analyzed traits was checked using the Shapiro-Wilk test. The results were compiled by one-way analysis of variance (ANOVA), and the significance of differences between means was determined by the LSD (Least Significant Difference) test.

\section{Results}

\section{Birds' performance}

The mean final body weight (FBW) of the birds was $2.35 \pm 0.04 \mathrm{~kg}$; body weight gain (BWG) was $2.02 \pm 0.03 \mathrm{~kg}$, and the feed conversion ratio (FCR) was $1.47 \pm 0.01 \mathrm{~kg}$ feed per kg BWG. None of the performance indices differed significantly either comparing between E1 and E2 treatments or comparing to control $(\mathrm{P}>0.05)$. 
Table 2. Sensory descriptors, their definitions, marks of the anchors used in the study

\begin{tabular}{|c|c|c|}
\hline Attribute & Definition & Anchors \\
\hline \multicolumn{3}{|c|}{ Odor } \\
\hline Heated meat & Aroma associated with heated meat & None to very strong \\
\hline Sour & Basic aroma sensation stimulated by acid & None to very strong \\
\hline Fatty & Aroma sensation derived from fat & None to very strong \\
\hline Other & The intensity and name or association & None to very strong \\
\hline \multicolumn{3}{|c|}{ Color } \\
\hline Tone & Degree of color from pink beige to brown & Pink beige-brown \\
\hline Homogeneity & Degree of color uniformity & \\
\hline \multicolumn{3}{|c|}{ Texture } \\
\hline Tenderness & Degree to which sample holds together on first bite & Non tender to very tender \\
\hline Juiciness & Impression of moisture release during chewing & Not juicy to very juicy \\
\hline \multicolumn{3}{|c|}{ Flavor, taste } \\
\hline Heated meat & Flavor associated with heated meat & None to very strong \\
\hline Sour & The basic taste sensation stimulated by acid & None to very strong \\
\hline Fatty & Aroma sensation derived from fat & None to very strong \\
\hline Salty & The basic taste sensation stimulated by salt & None to very strong \\
\hline Other & The intensity and name or association & None to very strong \\
\hline Overall quality & Impression based on all tested attributes & Very low to very high \\
\hline
\end{tabular}

Table 3. Parameters indicating the technological quality of the pectoral muscles (pectoralis major) of chickens at 36 days of age

\begin{tabular}{|c|c|c|c|c|c|c|}
\hline \multirow{2}{*}{\multicolumn{2}{|c|}{ Traits }} & \multicolumn{3}{|c|}{ Dietary treatments } & \multirow{2}{*}{ SEM } & \multirow{2}{*}{ P-value } \\
\hline & & $\mathrm{C}^{1}$ & $\mathrm{E} 1^{2}$ & $\mathrm{E} 2^{3}$ & & \\
\hline $\mathrm{pH}$ value & & 5.78 & 5.86 & 5.88 & 0.087 & 0.218 \\
\hline \multirow[t]{3}{*}{ Color parameters: } & $\mathrm{L}^{*}$ & 45.53 & 41.02 & 43.30 & 5.070 & 0.205 \\
\hline & $a^{*}$ & 1.22 & 1.38 & 1.90 & 1.497 & 0.507 \\
\hline & $\mathrm{b}^{*}$ & 13.36 & 12.97 & 12.95 & 3.973 & 0.901 \\
\hline \multicolumn{2}{|l|}{ Defrosting loss $(\%)$} & 4.57 & 3.40 & 3.78 & 1.070 & 0.255 \\
\hline \multicolumn{2}{|c|}{ Efficiency in heat treatment (\%) } & 70.66 & 70.87 & 70.32 & 3.200 & 0.602 \\
\hline
\end{tabular}

${ }^{1}$ Contained beef tallow $(80 \mathrm{mg} / \mathrm{kg}$ ) as the main source of fat and a basal level of vitamin E (40 mg/ $/ \mathrm{kg} \mathrm{diet})$.

${ }^{2}$ Contained a mixture of fish oil and beef tallow (50 g/ kg and $30 \mathrm{~g} / \mathrm{kg}$ diet, respectively) as the supplemental source of fat and a basal level of vitamin $\mathrm{E}$.

${ }^{3}$ As in diet E1 but with a graded vitamin E level $(120 \mathrm{mg} / \mathrm{kg}$ and $240 \mathrm{mg} / \mathrm{kg}$ diet on days $8-21$ and days $22-36$, respectively). Each value represents the mean of 9 replicates.

\section{Technological quality}

The results obtained in this research did not indicate a significant impact of the applied experimental diets on the technological quality or the chemical composition of the meat (Tables 3 and 4). The present report also demonstrated that all investigated indices, including parameters of technological quality of the pectoral muscle, and its basic chemical composition were similar as those in birds fed control diet. 
Table 4. Basic chemical composition of pectoral muscles (pectoralis major) in the experimental groups $(\%)$

\begin{tabular}{l|c|c|c|c|c}
\hline \multirow{2}{*}{ Components } & \multicolumn{3}{|c|}{ Dietary treatments } & \multirow{2}{*}{ SEM } & \multirow{2}{*}{ P-value } \\
\cline { 2 - 5 } & $\mathrm{C}^{1}$ & $\mathrm{E} 1^{2}$ & $\mathrm{E}^{3}$ & & \\
\hline Crude ash & 1.20 & 1.27 & 1.23 & 0.050 & 0.376 \\
Crude protein & 23.63 & 24.77 & 23.63 & 0.767 & 0.232 \\
Ether extract & 1.40 & 1.23 & 1.77 & 0.603 & 0.697 \\
Dry matter & 25.77 & 25.87 & 26.53 & 2.540 & 0.525 \\
\hline
\end{tabular}

${ }^{1}$ Contained beef tallow $(80 \mathrm{mg} / \mathrm{kg}$ ) as the main source of fat and a basal level of vitamin $\mathrm{E}$ ( $40 \mathrm{mg} / \mathrm{kg} \mathrm{diet})$.

${ }^{2}$ Contained a mixture of fish oil and beef tallow (50 g/ $/ \mathrm{kg}$ and $30 \mathrm{~g} / \mathrm{kg}$ diet, respectively) as the main source of fat and a basal level of vitamin E.

${ }^{3}$ As in diet E1 but with a graded vitamin E level $(120 \mathrm{mg} / \mathrm{kg}$ and $240 \mathrm{mg} / \mathrm{kg}$ diet on days 8-21 and days $22-36$, respectively). Each value represents the mean of 9 replicates.

Table 5. Fatty acid profiles of dietary fat sources and dietary treatments ( $\%$ of total fatty acids)

\begin{tabular}{|c|c|c|c|c|c|}
\hline \multirow{2}{*}{ Fatty acids } & \multicolumn{2}{|c|}{ Main dietary fat sources } & \multicolumn{3}{|c|}{ Dietary treatments } \\
\hline & beef tallow & fish oil & $\mathrm{C}^{1}$ & $\mathrm{E} 1^{2}$ & $\mathrm{E} 2^{3}$ \\
\hline $\mathrm{C} 16: 0$ & 26.1 & 10.8 & 23.5 & 15.9 & 15.9 \\
\hline C18:0 & 22.4 & 2.5 & 18.6 & 8.8 & 8.8 \\
\hline C18:1 & 34.2 & 35.5 & 32.5 & 34.0 & 33.4 \\
\hline C18:2n-6 (LA) & 1.68 & 11.4 & 11.7 & 16.1 & 16.7 \\
\hline C18:3n-3 (ALA) & trace & 4.1 & trace & 2.46 & 2.48 \\
\hline C20:4n-6 (AA) & trace & 0.4 & trace & 0.51 & 0.48 \\
\hline C20:5n-3 (EPA) & trace & 4.1 & trace & 2.0 & 2.1 \\
\hline C22:6n-3 (DHA) & trace & 4.9 & trace & 2.3 & 2.4 \\
\hline $\mathrm{SFA}^{4}$ & 53.9 & 17.3 & 46.4 & 28.1 & 28.0 \\
\hline MUFA $^{5}$ & 37.3 & 44.5 & 35.3 & 38.7 & 37.9 \\
\hline PUFA $^{6}$ & 8.8 & 38.2 & 18.3 & 33.2 & 34.1 \\
\hline PUFAn- $6^{7}$ & 15.0 & 13.1 & 12.0 & 17.3 & 17.8 \\
\hline PUFAn- $3^{8}$ & trace & 16.6 & trace & 8.5 & 8.6 \\
\hline PUFAn-6:n-3 & 15.0 & 0.79 & 12.0 & 2.0 & 2.1 \\
\hline
\end{tabular}

${ }^{1}$ Contained beef tallow $(80 \mathrm{mg} / \mathrm{kg})$ as the main source of fat and a basal level of vitamin $\mathrm{E}(40 \mathrm{mg} / \mathrm{kg} \mathrm{diet})$.

${ }^{2}$ Contained a mixture of fish oil and beef tallow $(50 \mathrm{~g} / \mathrm{kg}$ and $30 \mathrm{~g} / \mathrm{kg}$ diet, respectively) as the main source of fat and a basal level of vitamin E.

${ }^{3}$ As in diet E1 but with a graded vitamin E level $(120 \mathrm{mg} / \mathrm{kg}$ and $240 \mathrm{mg} / \mathrm{kg}$ diet on days $8-21$ and days 22-36, respectively).

${ }^{4} \mathrm{SFA}$ - saturated fatty acids $(\mathrm{C} 14: 0+\mathrm{C} 16: 0+\mathrm{C} 18: 0+\mathrm{C} 20: 0+\mathrm{C} 22: 0+\mathrm{C} 24: 0)$.

${ }^{5}$ MUFA - monounsaturated fatty acids $(\mathrm{C} 16: 1+\mathrm{C} 17: 1+\mathrm{C} 18: 1+\mathrm{C} 20: 1+\mathrm{C} 21: 1+\mathrm{C} 22: 1)$.

${ }^{6}$ PUFA - polyunsaturated fatty acids $(\mathrm{C} 18: 2 \mathrm{n}-6+\mathrm{C} 18: 3 \mathrm{n}-3+\mathrm{C} 18: 3 \mathrm{n}-6+\mathrm{C} 20: 2 \mathrm{n}-6+\mathrm{C} 20: 3 \mathrm{n}-6+$ C20:4n-6 + C20:5n-3 + C22:4n-6 + C22:5n-3+C22:6n3).

${ }^{7}$ PUFAn-6 (C18:2n-6 + C18:3n-6 + C20:2n-6 + C20:3n-6+C20:4n-6+C22:4n-6).

${ }^{8}$ PUFAn-3 (C18:3n-3 + C20:5n-3 + C22:5n-3 + C22:6n-3); trace - less than $0.05 \%$ of total fatty acids. Values are mean of 2 replicates. 
Fatty acid profile of dietary fat sources, dietary treatments and broiler meat

The FA profiles of the supplemental fat sources and the experimental diets are shown in Table 5. Compared to beef tallow, fish oil contained approximately 3-fold lower SFA content, similar MUFA content, and 4-fold higher PUFA content. n-3 PUFA were present in beef tallow at a trace level, whereas the fish oil contained high amounts of them. Consequently, the PUFA n-6:n-3 ratio in the control diet was approximately 7.5-fold higher than that in the diets supplemented with fish oil. n-3 LCPUFA, including ALA, EPA and DHA, were only found in the diets supplemented with fish oil. Inclusion of different fat sources in the diets significantly affected the FA profile of broiler breast meat (Table 6). Compared to the control treatment, feeding diets containing fish oil significantly decreased the content of arachidonic acid (AA) and increased the content of alpha-linolenic acid (ALA) in the breast meat $(\mathrm{P}=0.002$ and $\mathrm{P}<0.001$, respectively). Considering treatments with the different $\mathrm{vE}$ dose, the significant differences were found for LA $(\mathrm{P}=0.013)$ content and PUFA $n-6: n-3$ ratio being significantly higher $(\mathrm{P}<0.001)$ in breast meat of birds fed $\mathrm{E} 2$ treatment in each case. The atherogenicity index (AI) was found at the similar level between all treatments while the thrombogenicity index (TI) was similar between treatments E1 and E2 but was significantly higher than that in the control treatment $(\mathrm{P}<0.001)$.

Table 6 . Major fatty acid profiles ( $\%$ of total fatty acid content) and thrombogenic and atherogenicity indices of breast meat of broilers at 36 days of age

\begin{tabular}{|c|c|c|c|c|c|}
\hline \multirow{2}{*}{ Indices } & \multicolumn{3}{|c|}{ Dietary treatments } & \multirow{2}{*}{ SEM } & \multirow{2}{*}{ P-value } \\
\hline & $\mathrm{C}^{1}$ & $E 1^{2}$ & $\mathrm{E} 2^{3}$ & & \\
\hline$\overline{\mathrm{SFA}^{4}}$ & $34.4 \mathrm{a}$ & $39.1 \mathrm{~b}$ & $37.2 \mathrm{ab}$ & 0.74 & 0.028 \\
\hline UFA & 65.6 & 61.8 & 62.8 & 0.75 & 0.100 \\
\hline MUFA $^{5}$ & 41.5 & 43.1 & 41.8 & 0.65 & 0.603 \\
\hline PUFA $^{6}$ & $24.1 \mathrm{~B}$ & $18.6 \mathrm{~A}$ & $21.1 \mathrm{~A}$ & 0.72 & 0.006 \\
\hline C18:2n-6 LA & $15.2 \mathrm{~b}$ & $11.5 \mathrm{a}$ & $15.0 \mathrm{~b}$ & 0.57 & 0.013 \\
\hline C20:4n6 AA & $6.41 \mathrm{~B}$ & $3.61 \mathrm{~A}$ & $3.24 \mathrm{~A}$ & 0.430 & 0.002 \\
\hline C18:3n3 ALA & $0.72 \mathrm{~A}$ & $1.59 \mathrm{~B}$ & $1.65 \mathrm{~B}$ & 0.128 & 0.001 \\
\hline C20:5n3 EPA & $1.291 \mathrm{~B}$ & $0.341 \mathrm{~A}$ & $0.409 \mathrm{~A}$ & 0.0996 & 0.001 \\
\hline $\mathrm{C} 22: 5 \mathrm{n} 3 \mathrm{DPA}$ & 0.044 & 0.021 & 0.029 & 0.0042 & 0.081 \\
\hline C22:6n3 DHA & $0.024 \mathrm{~A}$ & $0.041 \mathrm{AB}$ & $0.059 \mathrm{~B}$ & 0.0046 & 0.003 \\
\hline PUFAn- $6^{7}$ & $22.3 \mathrm{~b}$ & $15.9 \mathrm{a}$ & $18.6 \mathrm{a}$ & 0.73 & 0.001 \\
\hline PUFAn- $3^{8}$ & 2.03 & 2.70 & 2.13 & 0.178 & 0.302 \\
\hline PUFAn6:n3 & $11.02 \mathrm{C}$ & $7.27 \mathrm{~A}$ & $8.94 \mathrm{~B}$ & 0.412 & 0.001 \\
\hline Thrombogenic index & $0.31 \mathrm{~A}$ & $0.48 \mathrm{~B}$ & $0.54 \mathrm{~B}$ & 0.027 & 0.001 \\
\hline Atherogenicity index & 0.32 & 0.31 & 0.34 & 0.013 & 0.582 \\
\hline
\end{tabular}

${ }^{1}$ Contained beef tallow $(80 \mathrm{mg} / \mathrm{kg})$ as the main source of fat and a basal level of vitamin $\mathrm{E}(40 \mathrm{mg} / \mathrm{kg} \mathrm{diet})$.

${ }^{2}$ Contained a mixture of fish oil and beef tallow (50 g/kg and $30 \mathrm{~g} / \mathrm{kg}$ diet, respectively) as the main source of fat and a basal level of vitamin $\mathrm{E}$.

${ }^{3}$ As in diet E1 but with a graded vitamin E level $(120 \mathrm{mg} / \mathrm{kg}$ and $240 \mathrm{mg} / \mathrm{kg}$ diet on days $8-21$ and days 22-36, respectively).

${ }^{4} \mathrm{SFA}$ - saturated fatty acids $(\mathrm{C} 14: 0+\mathrm{C} 16: 0+\mathrm{C} 18: 0+\mathrm{C} 20: 0+\mathrm{C} 22: 0+\mathrm{C} 24: 0)$.

${ }^{5}$ MUFA - monounsaturated fatty acids $(\mathrm{C} 16: 1+\mathrm{C} 17: 1+\mathrm{C} 18: 1+\mathrm{C} 20: 1+\mathrm{C} 21: 1+\mathrm{C} 22: 1)$.

${ }^{6}$ PUFA - polyunsaturated fatty acids $(\mathrm{C} 18: 2 \mathrm{n}-6+\mathrm{C} 18: 3 \mathrm{n}-3+\mathrm{C} 18: 3 \mathrm{n}-6+\mathrm{C} 20: 2 \mathrm{n}-6+\mathrm{C} 20: 3 \mathrm{n}-6+$ $\mathrm{C} 20: 4 \mathrm{n}-6+\mathrm{C} 20: 5 \mathrm{n}-3+\mathrm{C} 22: 4 \mathrm{n}-6+\mathrm{C} 22: 5 \mathrm{n}-3+\mathrm{C} 22: 6 \mathrm{n} 3)$.

${ }^{7}$ PUFAn-6 (C18:2n-6 + C18:3n-6 + C20:2n-6 + C20:3n-6 + C20:4n-6+C22:4n-6).

${ }^{8}$ PUFAn-3 (C18:3n-3 + C20:5n-3 + C22:5n-3 + C22:6n-3);

$\mathrm{A}, \mathrm{B}, \mathrm{C}-$ significant differences at $\mathrm{P}<0.01 ; \mathrm{a}, \mathrm{b}-$ significant differences at $\mathrm{P}<0.05$. Each value represents the mean of 9 replicates. 


\section{Sensory quality}

The results regarding the sensory qualities of the studied material are presented in Figure 1. The analysis of the obtained results showed that the highest overall quality was measured in breast meat from the birds, which were fed a diet similar as in the commercial conditions. The highest sensory quality of meat obtained from the control group was related to the high intensity of positive attributes such as the flavor and odor of the cooked meat and the low intensity of negative attributes such as fatty, sour, and off odor and flavor. In contrast, the addition of fish oil to the diet (E1) resulted in a significant decrease in the overall quality of the meat. This resulted from a decrease in the positive attributes of the meat and an increased intensity of negative notes such as fatty, sharp and off odor and flavor. But applying gradually increasing $\mathrm{vE}$ dose resulted in greater juiciness and tenderness of the breast meat in comparison to meat from birds fed diet of basal vE level and that of control. In consequence, the overall quality of the meat, which was still lower than that in the control group, was significantly higher than that of meat from chickens that received PUFA n-3-enriched diet but basal vE dose (E1 vs. E2).

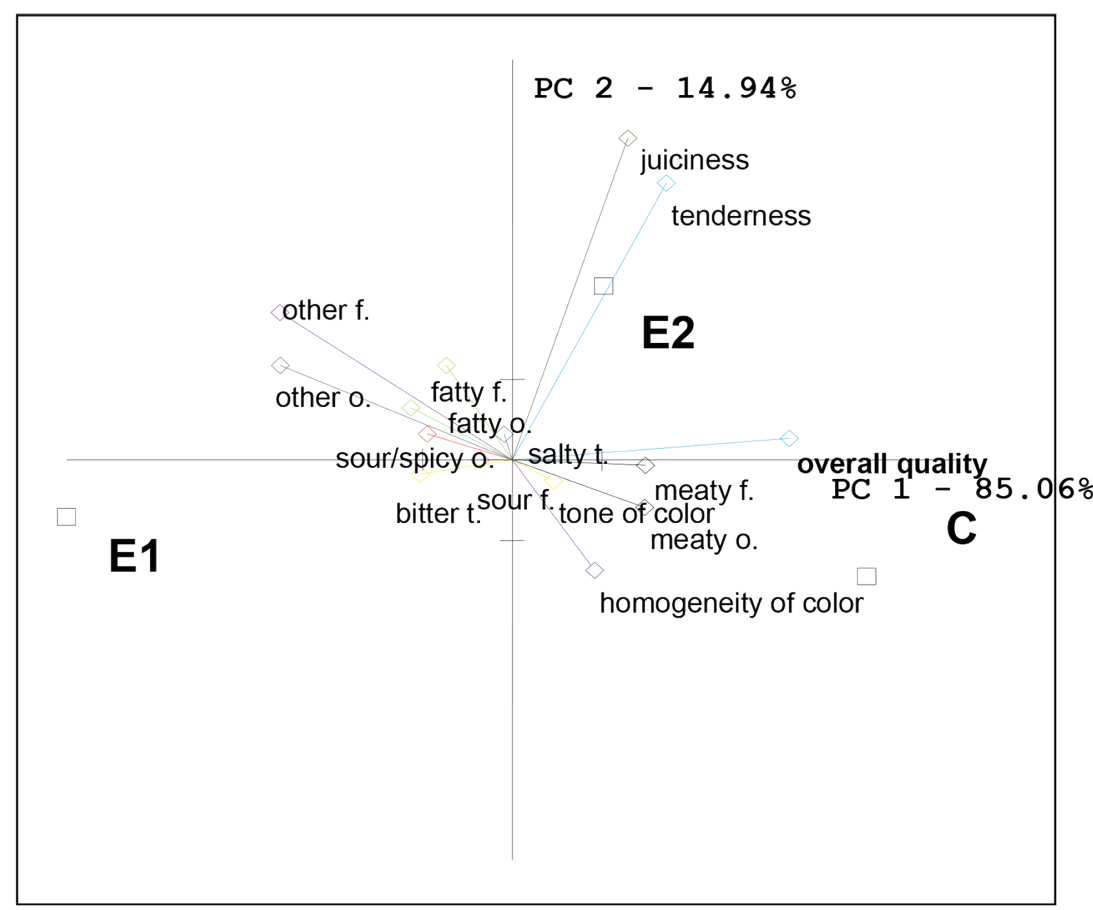

Figure 1. Principal component analysis of the matrix of mean sensory attributes obtained through the QDA rating method for chicken breast muscles (pectoralis major) obtained from animals in the control and experimental groups. Diet C contained beef tallow $(80 \mathrm{mg} / \mathrm{kg})$ as the main source of supplemental fat and a basal level of vitamin E (40 mg/ $\mathrm{kg}$ diet); Diet E1 contained a mixture of fish oil and beef tallow (50 g/ $/ \mathrm{kg}$ and $30 \mathrm{~g} / \mathrm{kg}$ diet, respectively) as the main source of supplemental fat and a basal level of vitamin E; Diet E2 was identical to diet E1 except that it featured a graded vitamin E level $(120 \mathrm{mg} / \mathrm{kg}$ and $240 \mathrm{mg} / \mathrm{kg}$ diet on days 8-21 and days 22-36, respectively); o - odor, $\mathrm{f}$ - flavor, $\mathrm{t}$ - taste 


\section{Oxidation status of fat}

The present report demonstrated a significant increase in MDA content in the meat of the chickens fed diets containing fish oil (Figure 2). The addition of vE, even at an increased dose, did not significantly reduce oxidative processes. However, the differences between both fish oil-supplemented diets were not significant.

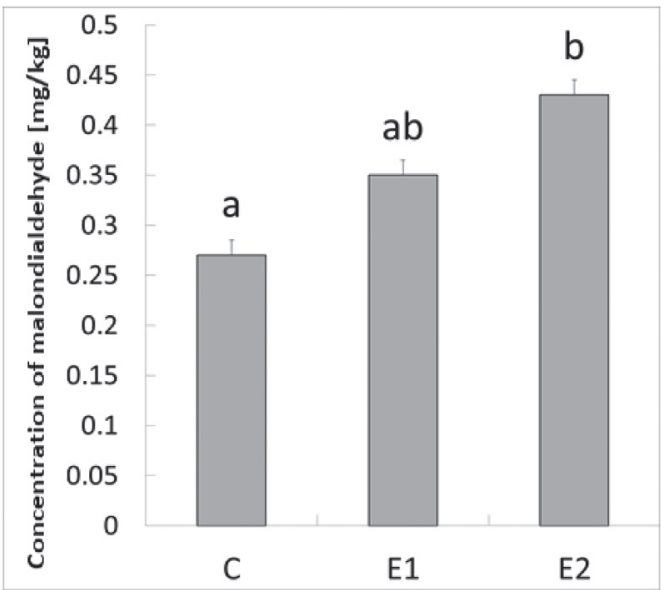

Figure 2. Malondialdehyde concentrations in chicken breast meat. Diet C contained beef tallow ( $80 \mathrm{mg} /$ $\mathrm{kg}$ ) as the main source of fat and a basal level of vitamin $\mathrm{E}(40 \mathrm{mg} / \mathrm{kg}$ diet $)$; Diet E1 contained a mixture of fish oil and beef tallow (50 g/ $\mathrm{kg}$ and $30 \mathrm{~g} / \mathrm{kg}$ diet, respectively) as the main source of fat and a basal level of vitamin E; Diet E2 was identical to diet E1 but featured a graded vitamin E level (120 mg/kg and $240 \mathrm{mg} / \mathrm{kg}$ diet on days 8-21 and days 22-36, respectively). a, b -indicate significant differences at $\mathrm{P}=0.05$. Each value represents the mean of 9 replicates
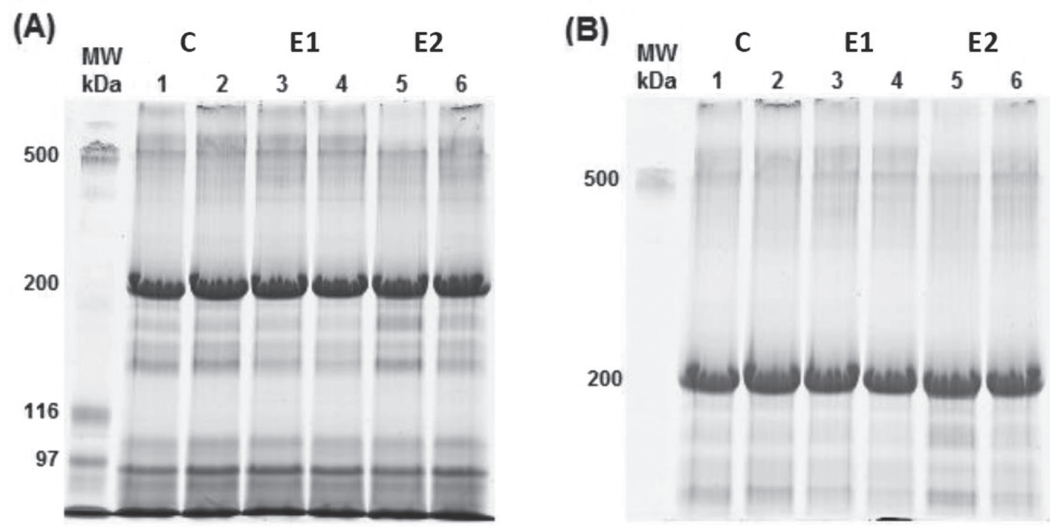

Figure 3. Samples separated by SDS-PAGE under non-reducing conditions over a period of $1.5 \mathrm{~h}(\mathrm{~A})$ and $2.5 \mathrm{~h}(\mathrm{~B})$. Diet C contained beef tallow $(80 \mathrm{mg} / \mathrm{kg})$ as the main source of supplemental fat and a basal level of vitamin E (40 mg/kg diet); Diet E1 contained a mixture of fish oil and beef tallow (50 g/ $\mathrm{kg}$ and $30 \mathrm{~g} / \mathrm{kg}$ diet, respectively) as the supplemental fat and a basal level of vitamin E; Diet E2 was identical to diet E1 but featured a graded vitamin E level $(120 \mathrm{mg} / \mathrm{kg}$ and $240 \mathrm{mg} / \mathrm{kg}$ diet on days 8-21 and days 22-36, respectively). Differences between treatments did not differ significantly $(\mathrm{P}=0.164$ for panel A and $\mathrm{P}=0.961$ for panel $\mathrm{B}$ ) 


\section{Protein oxidation status}

In this study, the separation of proteins extracted from muscles by SDS-PAGE under non-reducing conditions did not reveal the presence of proteins of high molecular weight exceeding the mass of myosin (above approximately $500 \mathrm{kDa}$ ) in the enriched meat (groups E1 and E2); the presence of such large protein complexes could indicate the polymerization of proteins as a result of their oxidation (Figure 3). The applied diagonal electrophoresis technique did not confirm the occurrence of the phenomenon of intermolecular protein cross-linking, especially MHC (myosin heavy chain) through the formation of disulphide bridges in samples of poultry meat (Figure 4).

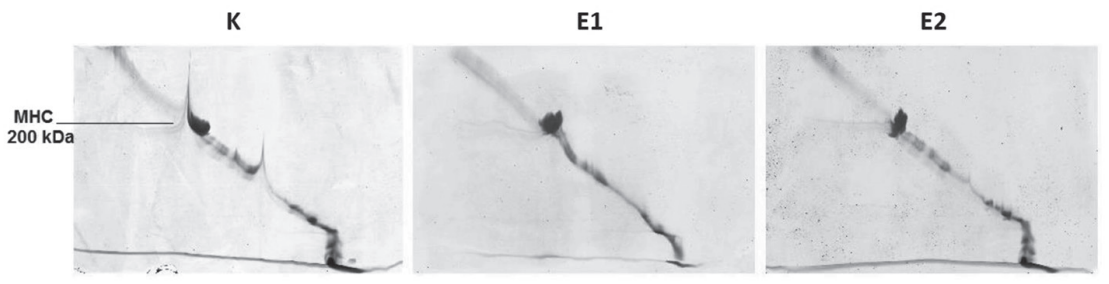

Figure 4. The samples separated by diagonal electrophoresis technique, in which non-reducing conditions were used in the first direction and reducing conditions in the second direction. No protein spots were observed outside the curve, indicating that no disulfide bridges were formed between the protein chains (no intermolecular or intramolecular cross-linking or polymerization of proteins). Diet $\mathrm{C}$ contained beef tallow $(80 \mathrm{mg} / \mathrm{kg})$ as the main source of fat and a basal level of vitamin $\mathrm{E}(40 \mathrm{mg} / \mathrm{kg} \mathrm{diet})$; Diet E1 contained a mixture of fish oil and beef tallow ( $50 \mathrm{~g} / \mathrm{kg}$ and $30 \mathrm{~g} / \mathrm{kg}$ diet, respectively) as the main source of fat and a basal level of vitamin E; Diet E2 was identical to diet E1 but featured a graded vitamin E level (120 mg/kg and $240 \mathrm{mg} / \mathrm{kg}$ diet on days 8-21 and days 22-36, respectively)

\section{Discussion}

The dietary treatments applied in the present study slightly affected indices determining technological quality of the breast meat of chickens including $\mathrm{pH}$ value, color parameters, defrosting loss, efficiency in heat treatment and basal chemical composition. The results of studies by other authors also did not show an effect of supplementing chicken feed with fish oil and various doses of $\mathrm{vE}$ on the $\mathrm{pH}$ value, color parameters or natural drip loss of meat (Muíño et al., 2014; Zhang et al., 2013). Similarly, Li et al. (2009) did not find an effect of different doses of $\mathrm{vE}$ in feed on color parameters or $\mathrm{pH}$ value; however, some studies have shown a significant effect of $v E$ dosage on natural drip loss from muscle tissue. An increase in vE dose from 10 to $200 \mathrm{mg} / \mathrm{kg}$ feed resulted in a significant decrease in the amount of natural drip loss. On the other hand, Zhang et al. (2013) showed a significant impact of vE supplementation on reducing losses during the cooking of poultry meat, while color parameters, $\mathrm{pH}$ value and natural drip loss were not affected. In turn, Osek et al. (2008) did not find that the addition of various fats of vegetable origin to the diet affected the degree of acidification of poultry meat, and Pietrzak et al. (2009) showed that the ad- 
dition of various antibacterial substances to the animals' feed did not cause a significant change in meat $\mathrm{pH}$. The results of the current research indicate a slight increase in the $\mathrm{pH}$ value of the meat; this was not, however, accompanied by an increase in cooking yield. A significant impact of $\mathrm{pH}$ on cooking yield was demonstrated in the studies of Pietrzak et al. (2013) and Jaworska and Przybylski (2014). Jakubowska et al. (2004) also showed a relationship between $\mathrm{pH}$ and efficiency in heat treatment. Meat with the highest $\mathrm{pH}$ value had less loss than meat with a lower $\mathrm{pH}$. Other studies have shown that the addition of fish oil to diets (control treatment vs. treatment E1) did not have a significant effect on the $\mathrm{pH}$ value of the meat of other species. In addition, the $\mathrm{pH}$ values obtained in this study are within the limits accepted as typical for poultry meat, which, according to Jakubowska et al. (2004), when measured 15 min after sampling should be between 5.9 and 6.2. Meat with $\mathrm{pH}$ below 5.7 is most often rated as defective PSE (Pale, Soft, Exudative), and meat with $\mathrm{pH}$ above 6.4 is rated as DFD (Dark, Firm, Dry).

We found that the dietary treatments applied herein exerted some beneficial actions in modulating breast lipids FA composition including AA and ALA concentrations, which are known to play important roles in maintaining biological systems, including the immune system and antioxidant systems. In birds exposed to stress stimuli, AA is released from membrane phospholipids and converted into various eicosanoids. In general, AA-derived eicosanoids act as proinflammatory molecules. Cherian (2007) reported that feeding broilers a typical commercial diet provides AA as a dominant substrate for eicosanoid synthesis. Interestingly, our earlier study (Konieczka et al., 2019) provided evidence for the regulatory action of acetylsalicylic acid in mediating AA metabolism in birds challenged with E. coli LPS; this regulatory action was particularly pronounced when supported with gradually increased doses of $\mathrm{vE}$ in the broiler diet. The increased deposition of ALA from the diet in the meat of birds has also been described previously (Jia et al., 2010). However, it must be stressed that a low rate of conversion of ALA to the more desirable LC-PUFA has been reported (Burdge, 2006). Thus, a particularly important finding of our report is that a beneficial contribution of PUFA n-3, including EPA and DHA, in broiler meat was observed when fish oil was substituted for the beef tallow used in the control diet. This also contributed to the significant decrease in the PUFA n-6:n-3 ratio in both of the experimental treatment groups. Although, vE dose in the diet did not play a significant role in the deposition of either EPA or DHA in the meat lipids. The nutritional value of meat to the consumer can be characterized according to its potential impact on health status. Thus, the indexes of AI and TI are used to demonstrate the nutritional value of meat. The first of these indicators expresses the relationship between the sum of the main saturated (proatherogenic) and unsaturated (antiatherogenic) FA, while the second estimates the risk of clot formation in the blood vessels and is expressed as the relationship between prothrombogenic and the antithrombogenic FA (Burdge, 2006). The present report demonstrates that AI did not show significant variations in the chickens in the experimental groups; although the TI was higher in the birds fed the diet containing a higher n-3 level, there were no significant differences between the groups supplemented with FO at different vE doses. There was, however, a significantly higher TI in E1 treatment comparing to 
control. This indicates that the use of a gradually increasing vE dose was effective in maintaining TI in birds fed PUFA n-3-enriched diet and that it has potential benefits with respect to the nutritional quality of the meat. In fact, the atherogenicity and thrombogenicity indices measured in the current work are lower than those reported by other authors (Attia et al., 2017; Zdanowska-Sasiadek et al., 2016), confirming the health-promoting properties of the broiler meat obtained in our study.

Ponnampalam et al. (2016) showed a significant effect of LC-PUFA on decreasing the sensory quality of meat. The negative impact is most frequently manifested as deterioration in odor and flavor. Ponnampalam et al. (2016) reported that linolenic acid is oxidized 20 to 30 times more rapidly than linoleic acid. In turn, linoleic acid undergoes negative oxidative changes 10 times faster than oleic acid. The authors of the cited study stated that oxidized fats may in turn affect the oxidation of myoglobin, which has a further negative influence on the sensory quality of the meat. The oxidation of fat and muscle proteins also leads to changes in meat color. Osek et al. (2005) studied the effect of feeding vegetable fats (soybean, rapeseed, sunflower and linseed oils) on the sensory quality of poultry meat. Sunflower oil and rapeseed in the mixture had a beneficial effect on the odor of meat, while the addition of linseed oil decreased the meat quality. In the case of soybean oil, a positive effect on chicken meat tenderness was observed. The results of Osek et al.'s (2008) study, in which the effects of feeding soybean oil, linseed oil, mixtures of the two, and $\mathrm{vE}$ was examined, showed that the best sensory quality of meat was obtained when the feed contained a higher proportion of soybean oil. Increased addition of linseed oil decreased its flavor. Although the use of plant-derived oils in broiler diets resulted in enrichment of the meat with PUFA, only the concentrations of LA and ALA increased, whereas EPA and DHA concentrations remained insufficient to improve the functional properties of the meat. Thus, using EPA and DHA derived from fish oil is an effective method of transferring FA to the edible parts of the carcass. This ensures the presence of nutritionally meaningful levels of EPA and DHA in broiler meat. The addition of antioxidant compounds (carnosine, selenium) to the feed definitely improves the sensory quality of meat. The results of our own research also indicate that increasing the vE levels in feed significantly improved the sensory qualities of chicken meat, especially its juiciness, tenderness and overall quality.

It was well documented that the increased dietary polyunsaturation level leads to deterioration in broiler meat properties while vE may counteract this process. In general, vE has inhibitory effects on oxidative processes (Konieczka et al., 2017 a, b; Li et al., 2009; Muíño et al., 2014; Niu et al., 2018; Pompeu et al., 2018; Ponnampalam et al., 2016; Voljč et al., 2013). However, some authors have found limited inhibition of fat oxidation or even pro-oxidative effects at increased doses of $\mathrm{vE}$ (above $200 \mathrm{mg} / \mathrm{kg}$ ) (Niu et al., 2018). The reason of contrary findings among reports might be of consequence that $\mathrm{vE}$ action depends on many factors, including birds' age and vE dose. In our previous study (Konieczka et al., 2018) we evidenced that increased levels of PUFA and $\mathrm{vE}$ had detrimental effect of lipid oxidation, and DNA damage of intestinal cells in birds at different age. But this negative effect mostly disappeared in birds at 42 day of age, suggesting that potential dietary intervention is more important at the earlier stage of the birds' growth. Therefore, in contrast to other reports in 
the present study we investigated effect of dietary increased PUFA level supported with the graded level of $\mathrm{vE}$ to maintain oxidation level in birds at the earlier stage of the growth. It has been shown that $\mathrm{vE}$ has a multifaceted effect on the oxidative stability of meat in that it reduces lipid oxidation, improves meat flavor and the stability of meat color, reduces natural drip loss, results in a general improvement of meat quality during the packaging and cooking process, and improves microbial stability (Ponnampalam et al., 2016). However, the effect depends to a large extent on the dose and duration of administration in the feed. Hence, vE levels in chicken feed should be adjusted according to the level of unsaturated fat in the diet. In general, supplementation of the diet with $\mathrm{vE}$ at increased doses inhibits oxidative processes in meat. However, a review (Ponnampalam et al., 2016) showed that increased levels of $\mathrm{vE}$ in the diet did not significantly reduce fat oxidation when a diet containing elevated levels of n-6 was fed to chickens. The present report demonstrates that although a diet in which the vE level is gradually increased does not significantly reduce the lipid oxidation rate in breast muscle comparing to birds' standard commercial diet. Thus, when the dose of $\mathrm{vE}$ in the diet is gradually increased, the pro-oxidative effect of excessive vE supplementation can likely be excluded. Jafari et al. (2012) stated that increased doses of vE might even induce oxidation of tissue lipids or could destroy intestinal cells through the increased free radicals formation and may have thus an adverse effect.

In addition to lipid oxidation, special attention should be given to protein oxidation. Although products of the oxidation of fat are relatively easily detectable in sensory evaluation, it is difficult to identify any adverse effects of protein oxidation products on sensory quality. Recent studies (Moczkowska et al., 2017) show that we are increasingly encountering muscle protein oxidation due to genetic pressure and/ or intensive nutrition. These processes usually lead to aggregation of proteins, reduction in their digestibility and a negative impact on consumer health (Estévez, 2011; Wójciak et al., 2019). Figure 3 and Figure 4 shows the results of SDS-PAGE and diagonal electrophoresis applied to control meat and meat from chickens in the experimental groups. This method, recently used by Moczkowska et al. (2017), allows for a more accurate assessment of the degree of muscle protein oxidation. If protein oxidation occurs, additional clusters appear above (containing intermolecular bonds) or below (containing disulfide bonds between molecules) the diagonal line. The position of MHC on the diagonal curve is marked (Figure 4). No protein spots were observed outside the curve indicating that no disulfide bridges were formed between protein chains. The SDS-PAGE and diagonal electrophoresis analyses also showed that there was no intermolecular and intramolecular cross-linking or polymerization of proteins, especially myosin, in broiler chicken meat samples. Similar protective effect of $v E$ against muscle protein oxidation in animals fed diets containing fish oil has been demonstrated in studies by Muíño et al. (2014). Ponnampalam et al. (2016) also reported that an increase in dietary $\mathrm{vE}$ level reduces muscle protein oxidation and protects meat against color changes. Although in the present study gradually increasing dose of $\mathrm{vE}$ did not result in a significant decrease in the concentration of MDA compared to the control treatment, it did neither significantly increase protein oxidation. These findings, together with that indicating beneficial shifts in the FA 
profile of the meat, suggest that including gradually increasing levels of $\mathrm{vE}$ in the diet may be considered an effective intervention in improving functional properties of the broiler meat.

\section{Conclusions}

The results of the present study indicate that supplementation of broiler chickens diet with FO did not significantly affect the technological quality of broiler meat compared to birds fed commercial diet. However, its sensory quality, as judged by odor, flavor, tenderness, juiciness and overall quality, was compromised, most likely due to oxidative changes in the fat. This negative effect was reduced to some extent by gradually increasing the amount of $\mathrm{vE}$ in the diet. The highest sensory quality and the lowest oxidative status of meat was found in control chickens. FO decreased the sensory quality of the meat and increased lipid oxidation as well as has an impact on lipid profile in muscle tissue (PUFA, n-3 ALA, EPA, DHA). Administration of a graded $\mathrm{vE}$ dose increased the sensory quality and did not limit lipid oxidation but maintained protein oxidation balance.

\section{References}

A t t i a Y.A., A l- H a r th i M.A., K or is h M.A., S h i b o o b M.M. (2017). Fatty acid and cholesterol profiles, hypocholesterolemic, atherogenic, and thrombogenic indices of broiler meat in the retail market. Lipids Health Dis., 16: 40.

Av i a g e n (2014). Ross 308 broiler nutrition specifications. Huntsville, Aviagen Group.

B u rd g e G.C. (2006). Metabolism of alpha-linolenic acid in humans. Prostaglandins Leukot. Essent. Fatty Acids, 75: 161-168.

Cheri a n G. (2007). Metabolic and cardiovascular diseases in poultry: role of dietary lipids. Poultry Sci., 86: 1012-1016.

Es téve z M. (2011). Protein carbonyls in meat systems: a review. Meat Sci., 89: 259-279.

Est e ve z M., P e tra c c i M. (2019). Benefits of magnesium supplementation to broiler subjected to dietary and heat stress: improved redox status, breast quality and decreased myopathy incidence. Antioxidants (Basel), 8: 456.

G i v e n s D.I. (2015). Manipulation of lipids in animal-derived foods: can it contribute to public health nutrition? Eur. J. Lipid Sci. Technol., 117: 1306-1316.

G i v e n s D.I., G i b b s R.A. (2008). Current intakes of EPA and DHA in European populations and the potential of animal-derived foods to increase them. Proc. Nutr. Soc., 67: 273-280.

ISO 1444 (2000). Meat and meat products. Free fat contents determination. Warsaw, Polish Committee for Standardization.

ISO 1871 (2009). Food and feed products - general guidelines for the determination of nitrogen by the Kjeldahl method. Geneva, ISO.

ISO 13299.2 (2003). Sensory analysis - methodology - general guidance for establishing a sensory profile. Geneva, ISO.

ISO 8586 (2012). Sensory analysis - General quietelines for the selection, training and monitoring of selected assessors and expert sensory assessors.

J a fari R.A., K i an i R., S hahriy ari A., A s a di F., H a mi din e j a t H. (2012). Effect of dietary vitamin $\mathrm{E}$ on plasma oxidative stress in broiler chicks infected with Eimeria tenella. Comp. Clin. Pathol., 21: 895-899.

Jakubowska M., Gardzielewska J., Kortz J., Karamucki T., Buryta B., Rybarc zyk A., O tolińska A., N a ta lczyk-Szymkowska W. (2004). Formation of physicochemical properties of broiler chicken breast muscles depending on $\mathrm{pH}$ value measured 15 minutes after slaughter (in Polish). Acta Sci. Pol. Technol. Aliment., 3: 139-144. 
Jaw or ska D., Przyby lski W. (2014). The effect of selected factors on sensory quality of pork. Food. Science. Technology. Quality, 21: 21-25.

J i a W., R o gi ew i c z A., B ru ce H.L., S l o m ins ki B.A. (2010). Feeding flaxseed enhances deposition of omega-3 fatty acids in broiler meat portions in different manner. Can. J. Anim. Sci., 90: 203-206.

K a la k u n t l a S.,N a g i r e d d y N.K.,P a n d a A.K.,J a t o th N.,T h i r u n a h a r i R., Va n g o o r R.R. (2017). Effect of dietary incorporation of $n-3$ polyunsaturated fatty acids rich oil sources on fatty acid profile, keeping quality and sensory attributes of broiler chicken meat. Anim. Nutr., 3: 386-391.

Konieczka P., Czauderna M., Rozbicka-Wieczorek A., S mulikowska S. (2015). The effect of dietary fat, vitamin $\mathrm{E}$ and selenium concentrations on the fatty acid profile and oxidative stability of frozen stored broiler meat. J. Anim. Feed Sci., 24: 224-251.

K onie czka P., Cza u derna M., S mulikows ka S. (2017 a). The enrichment of chicken meat with omega-3 fatty acids by dietary fish oil or its mixture with rapeseed or flaxseed - Effect of feeding duration: dietary fish oil, flaxseed, and rapeseed and n-3 enriched broiler meat. Anim. Feed Sci. Technol., 223: 42-52.

Kon ieczka P., R o z bi cka - Wi e c zorek A.J., C za uderna M., S mulikow ska S. (2017b). Beneficial effects of enrichment of chicken meat with n-3 polyunsaturated fatty acids, vitamin $E$ and selenium on health parameters: a study on male rats. Animal, 11: 1412-1420.

Konieczka P., Barszcz M., Choct M., Smulikowska S. (2018). The interactive effect of dietary n-6: n-3 fatty acid ratio and vitamin E level on tissue lipid peroxidation, DNA damage in intestinal epithelial cells, and gut morphology in chickens of different ages. Poultry Sci., 97: $149-158$.

Konieczka P., B arszcz M., Kow a lczyk P., S zl is M., Jankowski J. (2019). The potential of acetylsalicylic acid and vitamin $\mathrm{E}$ in modulating inflammatory cascades in chickens under lipopolysaccharide-induced inflammation. Vet. Res., 50: 65.

L i W.J., Z h a o G.P., C h e n J.L., Z h en g M.Q., We n J. (2009). Influence of dietary vitamin E supplementation on meat quality traits and gene expression related to lipid metabolism in the Beijingyou chicken. Brit Poultry Sci., 50: 188-198.

M c C a n n J.C., A me s B.N. (2005). Is docosahexaenoic acid, an n-3 long-chain polyunsaturated fatty acid, required for development of normal brain function? An overview of evidence from cognitive and behavioral tests in humans and animals. Am. J. Clin. Nutr., 82: 281-295.

Moczkowska M., Półtorak A., Montowska M., Pospiech E., Wierzbicka A. (2017). The effect of the packaging system and storage time on myofibrillar protein degradation and oxidation process in relation to beef tenderness. Meat Sci., 130: 7-15.

Muíño I., Apeleo E., de la Fuente J., Pérez-Santaescolástica C., Rivas-Cañedo A., Pérez C., Díaz M.T., Cañeque V., Lauzurica S. (2014). Effect of dietary supplementation with red wine extract or vitamin E, in combination with linseed and fish oil, on lamb meat quality. Meat Sci., 98: 116-123.

$\mathrm{Niu}$ Z., Min Y., Li u F. (2018). Dietary vitamin E improves meat quality and antioxidant capacity in broilers by upregulating the expression of antioxidant enzyme genes. J. Appl. Anim. Res., 46: $397-401$.

O s e k M., J a n o c ha A., M i l c za re k A., K l o c e k B. (2005). Productive and postslaughter results as well as meat flavour of broiler feed mixtures oiled with different plant oils (in Polish). Oilseed Crops, 26: 527-536.

O s e k M., M il c zarek A., J a n o ch a A. (2008). Impact of different shares of soybean and linseed oil in mixtures for broiler chicken on their growth, carcass value and meat quality characteristics (in Polish). Oilseed Crops, 29: 255-266.

Petrac ci M., S ogli a F., Madruga M., Carvalho L., Id a E., Estévez M. (2019). Wooden-breast, white striping, and spaghetti meat: causes, consequences and consumer perception of emerging broiler meat abnormalities. Compr. Rev. Food Sci. Food Saf., 18: 565-583.

Pietrzak D., Mroczek J., Garbaczewska A., Florowski T., Riedel J. (2009). Effects of selected antimicrobial feed additives on the quality of meat and fat of chickens. Vet. Med., 65: 268-271.

Pietrzak D., Michalczuk M., Niemiec J., Mroczek J., Adamczak L., Lukasiew i c z M. (2013). Comparison of selected quality attributes of meat originating from fast-and slow growing chickens. Food. Science. Technology. Quality, 20: 30-38. 
P o m p e u M.A., C a v a l c a n t i L.F.L., T or a 1 F.L.B. (2018). Effect of vitamin E supplementation on growth performance, meat quality, and immune response of male broiler chickens: a meta-analysis. Livest. Sci., 208: 5-13.

Ponn a m p a l m E.N., Holman B.W.B., Kerry J.P. (2016). The impact of animal nutrition on muscle composition and meat quality. In: Meat quality. Genetic and environmental factors, Przybylski W., Hopkins D. (eds.). CRC Press, Boca Raton, Taylor \& Francis Group, pp. 101-146.

Ribeiro T., Lordelo M.M., Alves S.P., Bess a R.J., Costa P., Lemos J.P., Ferreir a L.M., F o n t e s C.M., Pr a te s J.A. (2013). Direct supplementation of diet is the most efficient way of enriching broiler meat with n-3 long-chain polyunsaturated fatty acids. Brit. Poultry Sci., 54: 753-765.

Rymer C., Given s D.I. (2006). Effect of species and genotype on the efficiency of enrichment of poultry meat with n-3 polyunsaturated fatty acids. Lipids, 41: 445-451.

Rymer C., Given s D.I. (2010). Effects of vitamin E and fish oil inclusion in broiler diets on meat fatty acid composition and on the flavour of a composite sample of breast meat. J. Sci. Food Agric., 90: $1628-1633$.

Shahidi F. (1990). The 2-tiobarbituric acid (TBA) methodology for the evaluation of warmed-over flavour and rancidity in meat products. In: 36th International Congress of Meat Science and Technology, ICoMST, Cuba, pp. 1008-1014.

S m u lik ow ska S., R u tk ow ski A. (2005). Editors. Recommended allowances and nutritive value of feedstuffs - poultry feeding standards (in Polish). 4th ed. The Kielanowski Institute of Animal Physiology and Nutrition, PAS, Jabłonna (Poland).

Volj č M., L evart A., Zgur S., S a l o bi r J. (2013). The effect of $\alpha$-tocopherol, sweet chestnut wood extract and their combination on oxidative stress in vivo and the oxidative stability of meat in broilers. Brit. Poultry Sci., 54: 144-156.

Wang S., P a n Y., Li J., Ch en H., Z h a ng H., Ch en W., G u Z., Ch en Y.Q. (2017). Endogenous omega-3 long-chain fatty acid biosynthesis from alpha-linolenic acid is affected by substrate levels, gene expression, and product inhibition. RSC Adv., 7: 40946-40951.

Wój c iak K.M., Stas iak D.M., F erysiuk K., Solska E. (2019). The influence of sonication on the oxidative stability and nutritional value of organic dry-fermented beef. Meat Sci., 148: $113-119$.

Zd a now ska - S a s i a dek Z., M i chalc zuk M.,D a mazia k K., Ni e mie c J.,P o law ska E., Go z d ow ski D., R o z a n s k a E. (2016). Effect of vitamin E supplementation on growth performance and chicken meat quality. Eur. Poultry Sci., 80: 1-14.

Zh ang Y., S h a n A., J i ang W., B i C., L i Z. (2013). The effect of vitamin E on growth performance and meat quality in broilers given diets containing distillers' dried grain with solubles (DDGS). Brit. Poultry Sci., 54: 138-143.

Received: 3 VII 2020

Accepted: 25 II 2021 